\title{
The effects of prophylactic coronary revascularization or medical management on patient outcomes after noncardiac surgery - a meta-analysis
}

\author{
[Les effets de la revascularisation coronarienne prophylactique ou de la prise en charge \\ médicale sur le devenir des patients après une chirurgie non-cardiaque : une méta-analyse]
}

Elise Y.W. Wong DDS, * Herenia P. Lawrence PHD, $†$ David T. Wong MD* $\ddagger$

Purpose: The benefits of prophylactic coronary revascularization for patients undergoing noncardiac surgery are uncertain. The purpose of this study was to systematically evaluate the effect of coronary revascularization and medical management on short- and long-term outcomes after noncardiac surgery.

Method: Ten electronic databases including MEDLINE and EMBASE (1980 to February 2006), and bibliographies of included articles were searched without language restrictions. Studies comparing effects of coronary revascularization and medical management before noncardiac surgery were included. Patient outcome data including perioperative mortality, myocardial infarction, long-term mortality, or late adverse cardiac events were extracted and entered into a meta-analysis.

Results: The quality of published evidence was modest, comprising one randomized controlled trial and six retrospective studies. A total of 3,949 patients undergoing high-risk noncardiac surgery were included in the quantitative analysis. There was no significant difference between coronary revascularization and medical management groups with regards to postoperative mortality and myocardial infarction; the odds ratios ( $95 \%$ confidence intervals) were 0.85 (0.48-1.50) and 0.95 (0.44-2.08), respectively. There were no long-term outcome benefits associated with prophylactic coronary revascularization; the odds ratios (95\% confidence intervals) were 0.81 (0.40-I.63) and 1.65 (0.70-3.86) for long-term mortality and late adverse cardiac events, respectively.

Conclusion: In patients with stable coronary artery disease, prophylactic coronary revascularization before high-risk noncardiac surgery does not confer any beneficial effects, when compared with optimized medical management, in terms of perioperative mortality, myocardial infarction, long-term mortality, or adverse cardiac events.
CAN J ANESTH $2007 / 54: 9 /$ pp 705-717

Objectif : Les bienfaits de la revascularisation coronarienne prophylactique chez les patients subissant une chirurgie non cardiaque sont mal connus. L'objectif de cette étude était d'évaluer de façon systématique l'effet d'une revascularisation coronarienne et de la prise en charge médicale sur le devenir des patients après une chirurgie non cardiaque, à court et à long terme.

Méthode: Dix bases de données électroniques, y compris MEDLINE et EMBASE (1980 à février 2006), ainsi que les bibliographies des articles inclus, ont fait l'objet d'une recherche sans restriction de langue. Les études comparant les effets de la revascularisation coronarienne et de la prise en charge médicale avant une chirurgie non cardiaque ont été inclus dans la recherche. Les données concernant le devenir des patients, y compris la mortalité périopératoire, les infarctus du myocarde, la mortalité à long terme, et les événements cardiaques négatifs tardifs ont été extraites des études et analysées dans une méta-analyse.

Résultats: La qualité des données probantes publiées a été modeste, comprenant une étude randomisée contrôlée et six études rétrospectives. Au total, 3949 patients subissant une chirurgie non cardiaque à haut risque ont été inclus dans l'analyse quantitative. II n'y a pas eu de différence significative entre le groupe de revascularisation coronarienne et celui de prise en charge médicale quant à la mortalité postopératoire et à l'infarctus du myocarde ; les rapports de cotes (intervalles de confiance de $95 \%$ ) étaient de $0,85(0,48-1,50)$ et de 0,95 $(0,44-2,08)$, respectivement. Aucun bienfait sur le devenir à long terme n'a été associé à la revascularisation coronarienne prophylactique ; les rapports de cotes (intervalles de confiance de $95 \%)$ étaient de $0,81(0,40-1,63)$ et 1,65

From the Departments of Dental Anesthesia, ${ }^{*}$ Biological and Diagnostic Sciences, $\dagger$ Faculty of Dentistry; and the Department of Anesthesia, $\ddagger$ Toronto Western Hospital, University of Toronto, Toronto, Ontario, Canada.

Address correspondence to: Dr. David T. Wong, Department of Anesthesiology, MC 2-405, Toronto Western Hospital, 399 Bathurst

Street, Toronto, Ontario M5T 2S8, Canada. Phone: 416-603-5118; Fax: 416-603-6494; E-mail: david.wong@uhn.on.ca

This meta-analysis was undertaken as part of the requirements for the Master of Science degree in Dental Anaesthesia run by the Graduate

Department of Dentistry of the University of Toronto.

Accepted for publication January 12, 2007.

Revision accepted June 22, 2007. 
$(0,70-3,86)$ pour la mortalité à long terme et les effets cardiaques négatifs tardifs, respectivement.

Conclusion: Chez les patients avec une maladie coronarienne stable, la revascularisation coronarienne prophylactique avant une chirurgie non cardiaque à haut risque n'offre pas d'effets bénéfiques par rapport à une prise en charge médicale optimisée, en termes de mortalité périopératoire, d'infarctus du myocarde, de mortalité à long terme ou d'évènements cardiaques négatifs.

$\mathrm{P}$ ATIENTS with coronary artery disease (CAD) presenting for noncardiac surgery are at increased risk for perioperative cardiovascular events. ${ }^{1}$ These adverse events, including perioperative cardiac death and myocardial infarction, impact greatly on patients' quality of life and cost to the health-care system. ${ }^{2}$ Over the last two decades, much effort was spent on preoperative cardiac risk assessment and stratification., ${ }^{1,3-5}$ More recently, the paradigm is shifting to therapies, either interventional or medical, to minimize perioperative cardiac events. ${ }^{6-8}$

Coronary revascularization procedures, including coronary artery bypass graft surgery $(\mathrm{CABG})$, percutaneous transluminal coronary angiography, and coronary artery stenting (stent), have been shown to improve survival and quality of life in selected population of patients with CAD. ${ }^{9-12}$ However, the efficacy of prophylactic coronary revascularization prior to surgery in reducing perioperative risk is less well studied. Although coronary revascularization is currently part of the American College of Cardiology/American Heart Association (ACC/AHA) guideline for perioperative cardiovascular evaluation for noncardiac surgery algorithms, it is derived primarily from expert opinions and not based on strong evidence. ${ }^{13,14}$ Over the last decade, medical therapy such as beta-blockers, alpha-2 adrenergic agonists, calcium channel blockers, statin therapy and antiplatelet therapy have also been associated with reduced perioperative mortality, myocardial infarction or cardiac adverse events. ${ }^{15-21}$ The purpose of this study was to undertake a systematic review and meta-analysis comparing the effect of coronary revascularization and medical therapy on perioperative mortality and myocardial infarction, long-term mortality and late adverse cardiac events after noncardiac surgery.

\section{Methods}

With the assistance of an experienced reference librarian, a literature search was undertaken in February 2006 to identify all manuscripts regarding the short-

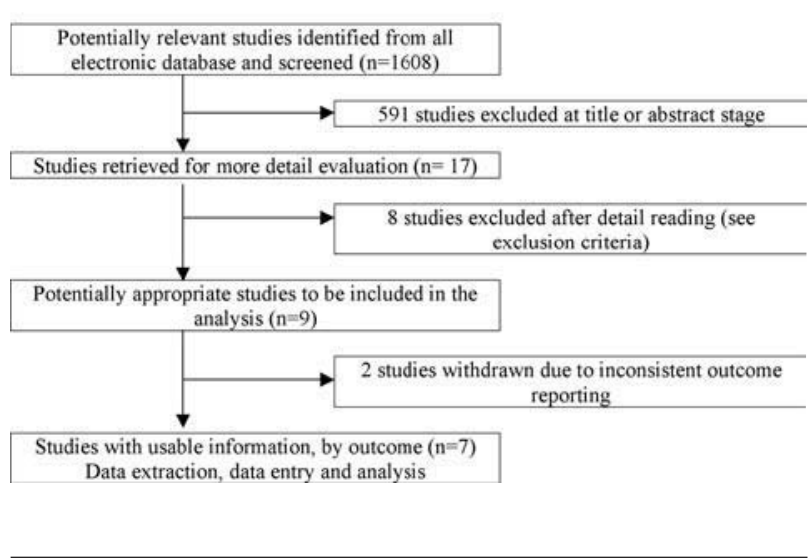

FIGURE 1 Process involved in study selection.

and long-term effect of myocardial revascularization vs medical management as pre-surgical management strategy. Ten electronic bibliographic databases were searched including MEDLINE (1966-2006), Embase (1980-2006) and Cochrane database of controlled trials.

Because only one randomized controlled clinical trial was available in the literature on our review topic, ${ }^{22}$ retrospective studies were also included in this review if they met the following criteria: enrolled adult patients with $\mathrm{CAD}$ who were undergoing noncardiac surgery; assessed and reported at least one patients' outcomes of concern (perioperative mortality and myocardial infarction, long-term mortality and late adverse cardiac events) following management with coronary revascularization or medical management before noncardiac surgery. Studies were excluded if they were published prior to 1980 due to significant advances in management of CAD disease since that time,${ }^{23}$ or if they were only comparing amongst coronary interventions or medical therapeutic agents. No restriction was applied to the language of publication. One investigator (E.W.) reviewed the title and abstracts of the studies to identify eligible manuscripts. The bibliographies of eligible articles were scanned and hand searched to identify additional articles. The search strategy and database are presented in Appendix A.

Data collection, quality assessment and analysis All eligible studies were reviewed. The following data were extracted: study design, type of surgery, patient and disease characteristics, preoperative management strategy; and patient outcome measures 
TABLE I Patient and disease characteristics in seven included studies

\begin{tabular}{|c|c|c|c|c|c|c|c|c|c|c|}
\hline $\begin{array}{l}\text { First author, } \\
\text { reference } \\
\text { location }\end{array}$ & $\begin{array}{l}\text { Sample } \\
C R / M M \text {, } \\
(n)\end{array}$ & $\begin{array}{l}\text { Enrolment } \\
(y r)\end{array}$ & $\begin{array}{l}\text { Mean } \\
\text { Age (yr) }\end{array}$ & $\begin{array}{l}D M \\
C R / M M \\
\%\end{array}$ & $\begin{array}{l}\text { Prior } M I \\
C R / M M, \\
\%\end{array}$ & $\begin{array}{l}\text { Severity of } C A D \\
C R / M M\end{array}$ & $\begin{array}{l}\text { Mean LVEF, } \\
C R / M M, \%\end{array}$ & $\begin{array}{l}\text { Follow-up, } \\
(y r)\end{array}$ & $\begin{array}{l}\text { CASP } \\
\text { score }\end{array}$ & $\begin{array}{l}\text { CTF } \\
\text { rating }\end{array}$ \\
\hline $\begin{array}{l}\text { Godet } 2005^{32} \\
\text { France }\end{array}$ & $78 / 1060$ & 1996-2002 & $67 \pm 11$ & $14 \% / 8 \%$ & $24 \% / 17 \%$ & $\begin{array}{l}\text { Clinically } \\
\text { symptomatic }(\%) \\
36 / 11\end{array}$ & ND & ND & $8 / 12$ & II-3 \\
\hline $\begin{array}{l}\text { McFalls }{ }^{22} \text { CARP } \\
\text { †trial } 2004 \\
\text { United States }\end{array}$ & $258 / 252$ & $1999-2003$ & $66 \pm 11$ & $19 \% / 20 \%$ & $43 \% / 40 \%$ & $\begin{array}{l}3 \text {-vessel CAD (\%) } \\
35.3 / 31.3 \\
\text { Among all included } \\
\text { patient revised } \\
\text { cardiac risk index: } \\
\geq 2 \text { risk factors } 49 \% \\
\geq 3 \text { risk factors } 13 \% \\
\text { Eagle's criteria: } \\
\geq 3 \text { risk factors } 28 \%\end{array}$ & $54 \% / 55 \%$ & 2.7 & $9.5 / 10$ & I \\
\hline $\begin{array}{l}\text { Takahashi } 2002^{30} \\
\text { Japan }\end{array}$ & $21 / 43$ & 1993-2002 & $66 \pm 9$ & ND & ND & $\begin{array}{l}\% \text { Stenosis in } \geq \text { one } \\
\text { major coronary } \\
\text { artery or its main } \\
\text { branch: } 75 / 50\end{array}$ & ND & 2.6 & $7 / 12$ & II-3 \\
\hline $\begin{array}{l}\text { Back } 2002^{28} \\
\text { United States }\end{array}$ & $128 / 353$ & $1996-2000$ & $70 \pm 1$ & $42 \% / 28 \%$ * & $54 \% / 20 \%$ * & $\begin{array}{l}\% \text { Patient with } 2 \text { or } \\
3 \text { vessel disease: } \\
19 / 7 \\
\text { Eagle's criteria: }\end{array}$ & $\begin{array}{l}\% \text { patient with } \\
\text { LVEF < 35\%: } \\
19 \% / 4 \%\end{array}$ & & $6 / 12$ & II-3 \\
\hline $\begin{array}{l}\text { Back } 2004^{29} \\
\text { United States }\end{array}$ & $128 / 353$ & $1996-2000$ & $70 \pm 1$ & $42 \% / 28 \% *$ & $54 \% / 20 \% *$ & $\begin{array}{l}\% \text { Patient with } \geq 3 \\
\text { risk factors: } 27 / 7\end{array}$ & & 5 & & \\
\hline $\begin{array}{l}\text { Eagle } 1997^{27} \\
\text { United States }\end{array}$ & $964 / 582$ & 1974-1979 & $>60$ & ND & ND & ND & ND & ND & $4 / 12$ & II-3 \\
\hline
\end{tabular}

$\mathrm{CR}=$ coronary revascularization; $\mathrm{MM}=$ medical management. $\mathrm{DM}=$ diabetes mellitus; CAD = coronary artery disease; LVEF $=$ left ventricular ejection fraction; CASP = Canadian Appraisal Skill Program; CTF = Canadian Task Force; ND = no data available; NYHA = New York Heart Association; CCS $=$ Canadian Cardiovascular Society Angina Classification. ${ }^{*} \mathrm{P}<0.05$ between CR and MM. †CARP trial, the only randomized control trial available. The other six studies are retrospective studies.

(pre- and post-noncardiac surgery mortality, postoperative myocardial infarction, long-term mortality, and late adverse cardiac events). Mortality included death due to all causes. The quality of each study was assessed using appraisal tools developed by the Critical Appraisal Skill Program (CASP) (Appendix B) ${ }^{24}$ and rated in accordance with the Canadian Task Force on Preventive Health Care's guidelines for grading quality of published evidence (Appendix C). ${ }^{25}$ Grading of recommendations was based upon the grading system established by the Canadian Task Force (CTF) for Specific Clinical Preventive Actions (Appendix D). ${ }^{25}$

\section{Statistical analysis}

Effects of the two risk reduction strategies, namely prophylactic coronary revascularization and medical management, were analyzed using the odds ratio (OR) the primary outcome measure. Statistical analyses were performed using RevMan 4.2.10 (Cochrane Collaboration, Oxford, UK). The DerSimonian and Laird random effects model was used to calculate the pooled OR $[95 \%$ confidence interval (CI)]. A sensitivity analysis was then conducted by comparing this pooled $\mathrm{OR}$ value with that calculated without the randomized controlled clinical trial. For each outcome measure, between-study heterogeneity was evaluated with the $\chi^{2}$-based $Q$ statistic and considered significant at $P<0.10 .^{26}$

We hypothesized, a priori, that factors such as study quality, length of time between preoperative coronary revascularization intervention and noncardiac surgery, and duration of follow-up could explain the differences in outcomes. Subgroup analyses were conducted to examine whether the outcome results were different in studies in which coronary revascularizations were performed after patient enrolment vs those in which coronary revascularizations were performed prior to patient enrolment, and in studies which enrolled patients after 1980 vs studies that enrolled patients before 1980 . 
TABLE II Number of patients and incidence of events of perioperative outcomes for coronary revascularization vs medical management groups. The pooled random effect odds ratios, $95 \%$ confidence interval and P-values for heterogeneity measure for the three outcomes are provided.

\begin{tabular}{|c|c|c|c|c|c|c|c|c|c|c|c|c|}
\hline \multirow[b]{3}{*}{ Study } & \multicolumn{4}{|c|}{ Pre-NCS death } & \multicolumn{4}{|c|}{ Post-NCS death } & \multicolumn{4}{|c|}{ Post-NCS MI } \\
\hline & \multicolumn{2}{|c|}{$C R$} & \multicolumn{2}{|l|}{$M M$} & \multicolumn{2}{|l|}{$C R$} & \multicolumn{2}{|l|}{$M M$} & \multicolumn{2}{|l|}{$C R$} & \multicolumn{2}{|l|}{$M M$} \\
\hline & $\mathrm{n} / \mathrm{N}$ & $\%$ & $\mathrm{n} / \mathrm{N}$ & $\%$ & $\mathrm{n} / \mathrm{N}$ & $\%$ & $\mathrm{n} / \mathrm{N}$ & $\%$ & $\mathrm{n} / \mathrm{N}$ & $\%$ & $\mathrm{n} / \mathrm{N}$ & $\%$ \\
\hline Garofalo $2005^{31}$ & $0 / 83$ & $0 \%$ & $1 / 127$ & $0 \%$ & $0 / 83$ & $0 \%$ & $2 / 127$ & $1.6 \%$ & $0 / 83$ & $0 \%$ & $0 / 127$ & $0 \%$ \\
\hline Godet $2005^{32}$ & $0 / 78$ & $0 \%$ & $0 / 1060$ & $0 \%$ & $4 / 78$ & $5.1 \%$ & $44 / 1060$ & $4.2 \%$ & $7 / 78$ & $8.9 \%$ & $67 / 1060$ & $6.3 \%$ \\
\hline $\begin{array}{l}\text { McFalls CARP } † \\
\text { trial } 2004^{22}\end{array}$ & $10 / 258$ & $3.9 \%$ & $1 / 252$ & $0.39 \%$ & $7 / 225$ & $3.1 \%$ & $8 / 237$ & $3.4 \%$ & $19 / 225$ & $8.4 \%$ & $20 / 237$ & $8.4 \%$ \\
\hline Takahashi $2002^{30}$ & $1 / 21$ & $4.8 \%$ & $0 / 43$ & $0 \%$ & $0 / 21$ & $0 \%$ & $2 / 43$ & $2.3 \%$ & ND & ND & ND & ND \\
\hline Back $2002^{28}$ & ND & ND & ND & ND & $4 / 128$ & $3.1 \%$ & $4 / 353$ & $1.1 \%$ & $6 / 128$ & $4.7 \%$ & $8 / 353$ & $2.3 \%$ \\
\hline Back $2004^{29}$ & ND & ND & ND & ND & ND & ND & ND & ND & ND & $\mathrm{ND}$ & ND & ND \\
\hline Eagle $1997^{27}$ & ND & ND & ND & ND & $16 / 964$ & $1.7 \%$ & $19 / 582$ & $3.3 \%$ & $8 / 964$ & $0.83 \%$ & $16 / 582$ & $2.8 \%$ \\
\hline $\begin{array}{l}\text { Total including } \\
\text { CARP trial }\end{array}$ & $11 / 440$ & $2.5 \%$ & $2 / 1482$ & $0.13 \%$ & $31 / 1499$ & $2.1 \%$ & $79 / 2402$ & $3.3 \%$ & $40 / 1478$ & $2.7 \%$ & $111 / 2359$ & $4.7 \%$ \\
\hline $\begin{array}{l}\text { RE odds ratio } \\
(95 \% \mathrm{CI}) \text { including } \\
\text { CARP trial }\end{array}$ & & $\begin{array}{r}8.86(1 \\
\text { P (heterog }\end{array}$ & $\begin{array}{l}55-50.5) \\
\text { eneity) }=0.8\end{array}$ & & & $\begin{array}{r}0.85 \\
\text { P (hetero }\end{array}$ & $\begin{array}{l}48-1.50) \\
\text { neity }=0.27\end{array}$ & & & $\begin{array}{r}0.95( \\
\text { (heterog }\end{array}$ & $\begin{array}{l}4-2.08) \\
\text { eity }=0.02\end{array}$ & \\
\hline $\begin{array}{l}\text { Total excluding } \\
\text { CARP trial }\end{array}$ & $1 / 182$ & $0.55 \%$ & $1 / 1230$ & $0.081 \%$ & $24 / 1274$ & $1.9 \%$ & $71 / 2165$ & $3.3 \%$ & $21 / 1253$ & $1.7 \%$ & $91 / 2122$ & $4.3 \%$ \\
\hline $\begin{array}{l}\text { RE odds ratio } \\
\text { ( } 95 \% \mathrm{CI} \text { ) excluding } \\
\text { CARP trial }\end{array}$ & & $\begin{array}{r}6.37(0 \\
\text { (heteroge }\end{array}$ & $\begin{array}{l}25-163) \\
\text { neity) = NA }\end{array}$ & & & $\begin{array}{r}0.87 \\
\text { (heteros }\end{array}$ & $\begin{array}{l}1-1.88) \\
\text { heity) }=0.18\end{array}$ & & & $\begin{array}{r}0.95 \\
\text { (heterog }\end{array}$ & $\begin{array}{l}9-3.14) \\
\text { ity) }=0.006\end{array}$ & \\
\hline
\end{tabular}

$\mathrm{CR}=$ coronary revascularization, $\mathrm{MM}=$ medical management, $\mathrm{NCS}=$ noncardiac surgery $\mathrm{MI}=$ myocardial infarction; $\mathrm{ND}=$ no data available. $\mathrm{NA}=$ not available; $\mathrm{RE}=$ random effects. $\mathrm{CI}=$ confidence interval. †CARP trial, the only randomized control trial available. The other six studies are retrospective studies.

\section{Results}

Of the 1,608 articles identified, 1,591 articles were rejected at the title and abstract stage; 17 articles were reviewed in detail. After full article readings, seven manuscripts comprising 3,949 patients were included. ${ }^{22,27-32}$ Ten articles were rejected due to various reasons: lack of comparison with medical management, ${ }^{33,34}$ lack of subsequent noncardiac surgery, ${ }^{35-41}$ and outcome report inconsistent with our review criteria $^{42,43}$ (Figure 1).

Data were extracted from these seven trials published between 1997 and 2005, one randomized controlled trial, ${ }^{22}$ and six retrospective studies. ${ }^{27-32}$ Patients from most studies were scheduled for elective major vascular surgery; only one study involved high-risk noncardiac surgery. ${ }^{27}$ Duration of long-term follow-up ranged from 31 months to 56 months. The mean age of participants ranged from 60 to $70 \mathrm{yr}$. Two studies reported short- and long-term outcomes on the same group of patients respectively. ${ }^{28,29}$ There were substantial variations in incidence of diabetes, prior myocardial infarction and severity of CAD among the studies (Table I). Moreover, only $28 \%$ and $34 \%$ of patients from McFalls ${ }^{22}$ and Back' ${ }^{28,29}$ studies had three or more Eagle's cardiac risk criteria, suggesting lower cardiac risk study populations.

\section{Quality assessment}

Except McFalls et al., which is a randomized controlled clinical trial (CARP trial), ${ }^{22}$ the six retrospective studies had inherited flaws in their study design resulting in fair to low CASP scores ${ }^{24}$ (Table I).

\section{Pre-noncardiac surgery mortality, postoperative mor- tality and postoperative myocardial infarction}

The number (\%) of events for the three perioperative outcomes are shown for the seven studies (Table II). The pooled random effect OR, 95\% CI and $P$-values for heterogeneity measure for the seven studies, and for the six studies excluding the CARP trial, are also shown. Except for the pre-noncardiac surgery mortality, pooled data from all studies resulted in similar random effect OR and 95\% CI as those from the analyses performed without the CARP trial ${ }^{22}$ (Table II).

Four studies ${ }^{22,30-32}$ reported death occurring after patient allocation before noncardiac surgery; 11 preoperative deaths occurred among 440 patients receiving prophylactic coronary revascularization, while two 


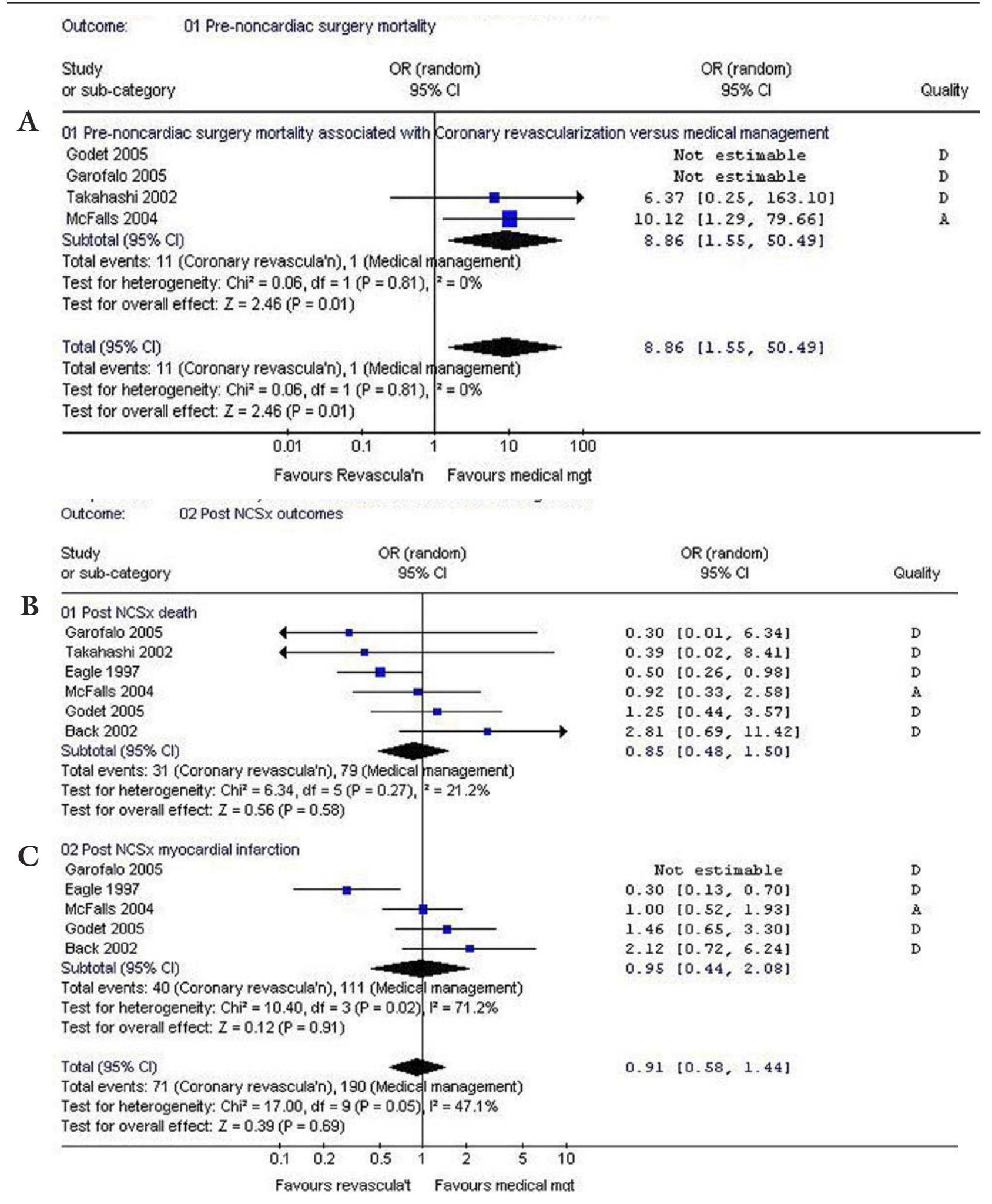

FIGURE 2 Comparison of coronary revascularization $v s$ medical management for: (A) preoperative mortality, (B) postoperative mortality, and (C) postoperative myocardial infarction. Each study is shown by name along with point estimate of odds ratios and respective $95 \%$ confidence intervals. In each panel, size of box denoting point estimate in each study is proportional to weight of the study. 
TABLE III Number of patients and incidence of events of long-term outcomes for coronary revascularization vs medical management groups The pooled random effect odds ratios, $95 \%$ confidence intervals and $P$-values for heterogeneity measure for the outcomes are provided.

\begin{tabular}{|c|c|c|c|c|c|c|c|c|}
\hline \multirow[b]{3}{*}{ Study } & \multicolumn{4}{|c|}{ Long-term mortality } & \multicolumn{4}{|c|}{ Late adverse cardiac event ${ }^{*}$} \\
\hline & \multicolumn{2}{|c|}{$C R$} & \multicolumn{2}{|c|}{$M M$} & \multicolumn{2}{|c|}{$C R$} & \multicolumn{2}{|c|}{$M M$} \\
\hline & $\mathrm{n} / \mathrm{N}$ & $\%$ & $\mathrm{n} / \mathrm{N}$ & $\%$ & $\mathrm{n} / \mathrm{N}$ & $\%$ & $\mathrm{n} / \mathrm{N}$ & $\%$ \\
\hline Garofalo $2005^{31}$ & & $5 \pm 2.8 \%$ & & $20 \pm 11 \%$ & & $11 \pm 6$ & & $9 \pm 6.6 \%$ \\
\hline Godet $2005^{32}$ & ND & ND & ND & ND & ND & ND & ND & ND \\
\hline McFalls CARP $†$ trial $2004^{22}$ & & $22 \%$ & & $23 \%$ & ND & ND & ND & ND \\
\hline Takahashi $2002^{30}$ & $0 / 21$ & $0 \%$ & $0 / 43$ & $0 \%$ & $3 / 20$ & $15 \%$ & $2 / 41$ & $4.9 \%$ \\
\hline Back $2002^{28}$ & ND & ND & ND & ND & ND & ND & ND & ND \\
\hline Back $2004^{29}$ & & $32 \%$ & & $25.6 \%$ & $35 / 111$ & $31.5 \%$ & $48 / 285$ & $16.5 \%$ \\
\hline Eagle $1997^{27}$ & ND & ND & ND & ND & ND & ND & ND & ND \\
\hline $\begin{array}{l}\text { Total including CARP trial } \\
\text { RE odds ratio }\end{array}$ & $96 / 463$ & $20.7 \%$ & $158 / 714$ & $22.1 \%$ & $45 / 214$ & $21 \%$ & $64 / 453$ & $13.8 \%$ \\
\hline $\begin{array}{l}(95 \% \mathrm{CI}) \text { including } \\
\text { CARP trial }\end{array}$ & & $\begin{array}{r}0.81 \\
\mathrm{P} \text { (heterog }\end{array}$ & $\begin{array}{l}-1.63) \\
\text { ty })=0.01\end{array}$ & & & $\begin{array}{r}1.65 \\
P \text { (heterc }\end{array}$ & $\begin{array}{l}\text { 36) } \\
=0.10\end{array}$ & \\
\hline $\begin{array}{l}\text { Total excluding CARP trial } \\
\text { RE odds ratio }\end{array}$ & $41 / 214$ & $19.2 \%$ & $98 / 453$ & $21.6 \%$ & $41 / 214$ & $19.2 \%$ & $98 / 453$ & $21.6 \%$ \\
\hline (95\% CI) excluding & & $0.64(0$ & 3.34) & & & 1.65 & 86) & \\
\hline CARP trial & & $\mathrm{P}$ (heteroge & $=0.003$ & & & $\mathrm{P}$ (heterc & $=0.10$ & \\
\hline
\end{tabular}

$\mathrm{CR}=$ coronary revascularization; $\mathrm{MM}=$ medical management; $\mathrm{NCS}=$ noncardiac surgery; ND = no data available; RE = random effects; $\mathrm{CI}=$ confidence interval. *As defined by: Garofalo, 2005: recurrent angina, myocardial infarction, or cardiac ischemia; Takahashi, 2002: patients requiring repeated coronary revascularization during follow-up period; Back, 2004: myocardial infarction, unstable angina, congestive heart failure, ventricular arrhythmia; †CARP trial, the only randomized control trial available. The other six studies are retrospective studies.

preoperative deaths occurred among 1,482 patients receiving medical management. The odds of mortality during pre-noncardiac surgery period was increased when patients had prophylactic coronary revascularization compared with medical management (OR, 8.86 ; 95\% CI, 1.55-50.5). When the OR was calculated excluding the CARP trial, the 95\% CI widened significantly, but the odds of pre-noncardiac surgery mortality remained high $(\mathrm{OR}, 6.37 ; 0.25-163)$ among patients with coronary revascularization.

Meta-analyses of perioperative outcomes from the included studies are shown (Figure 2, A-C). There is non-significant level of heterogeneity for pre-noncardiac surgical mortality, as well as postoperative mortality with and without the CARP trial (Table II). However, a high level of heterogeneity was observed across the studies for postoperative myocardial infarction including or excluding the CARP trial $(P=0.02$ and 0.006 , respectively).

\section{Long-term mortality and late adverse cardiac event}

The numbers (\%) of events for the long-term outcomes are shown for the relevant studies (Table III). The pooled random effect OR, 95\% CI and $P$-values for heterogeneity measure for all relevant studies, and for the retrospective studies excluding CARP are shown. Overall, pooled data from all relevant studies resulted in similar OR as those from the analyses performed without the CARP trial. Meta-analyses of long-term outcomes (Figure 3, A and B) demonstrate that the odds of long-term mortality and late adverse cardiac events did not differ between patients who received prophylactic coronary revascularization and medical management.

In addition, the meta-analyses also showed a high level of heterogeneity across the trials regardless of whether the CARP trial was included or excluded ( $P$ $=0.01$ and 0.003 , respectively); while the meta-analysis for late adverse cardiac events outcome showed a borderline significant level of heterogeneity across the three retrospective studies $(P=0.10)$, suggesting these follow-up results are too dissimilar to be combined meaningfully.-

\section{Bias and subgroup analysis}

To help detect any potential biases (e.g., publication bias), a funnel plot was constructed from the postsurgical mortality outcome. Figure 4 revealed an asymmetrical plot of the results from all six relevant studies (including the randomized controlled trial) in 


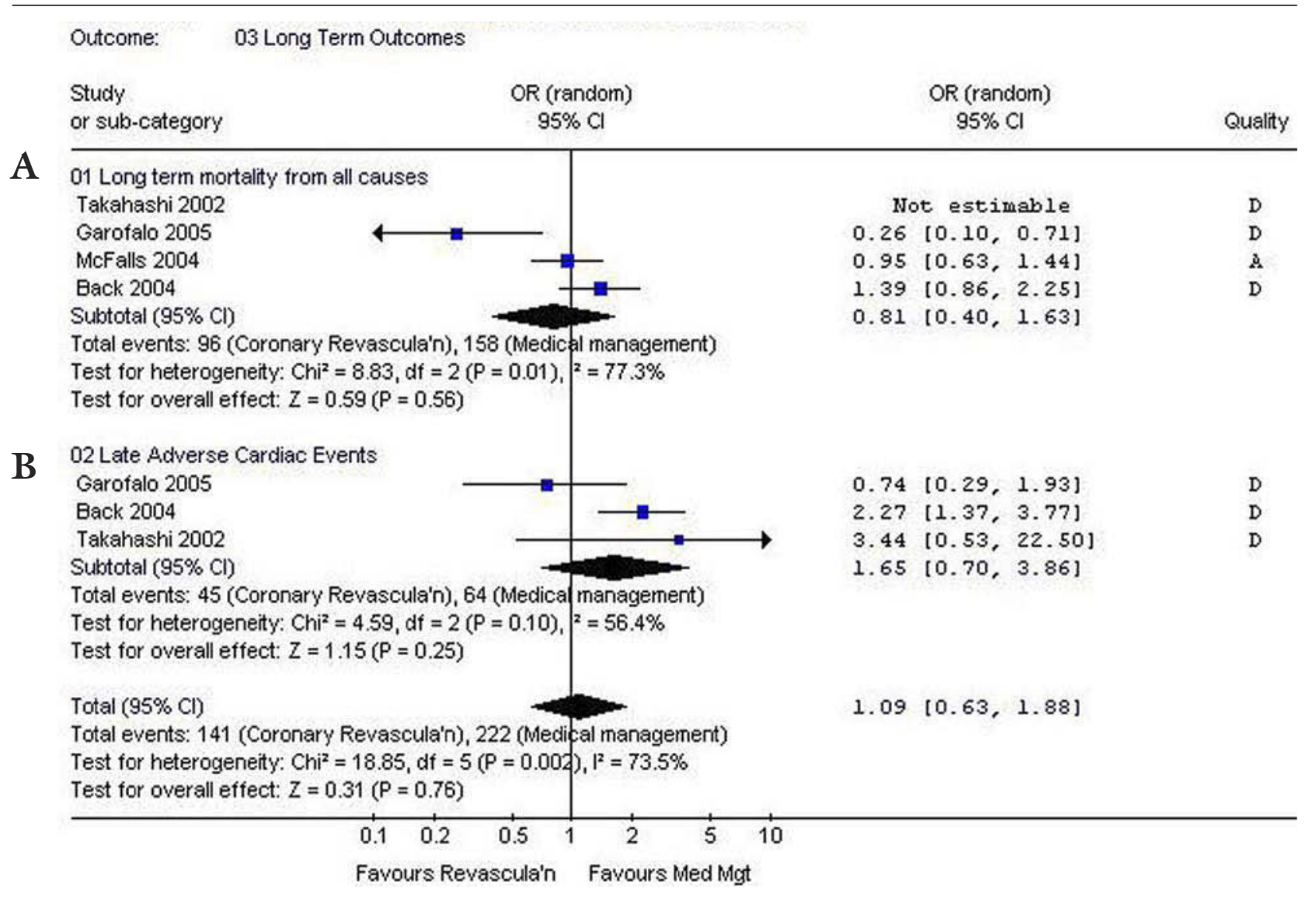

FIGURE 3 Comparison of coronary revascularization vs medical management for: (A) long-term mortality and (B) delayed adverse cardiac events. Each study is shown by name along with point estimate of odds ratios and respective $95 \%$ confidence intervals. In each panel, size of box denoting point estimate in each study is proportional to weight of study.

which the two smaller studies by Takahashi et $a l .{ }^{30}$ and Garofalo et al. ${ }^{31}$ landed more widely at the bottom left of the plot. For postoperative mortality outcome, these two smaller studies with fewer events showed a more favourable OR with coronary revascularization vs medical management than larger trials with more events (Figure 2A). However, the pooled OR without these two studies did not differ significantly (OR 0.96, 95\% CI 0.48-1.91; data not shown).

Another factor contributing to heterogeneity of effect size was the patients' baseline severity of CAD. The CARP trial studied patients with intermediate or minor cardiac risk factors, ${ }^{44}$ while in most of the retrospective studies, patients with more significant CAD were allocated to coronary revascularization group and patients with less significant $\mathrm{CAD}$ to the medical management group (Table I). Thus, there is a probable patient selection bias amongst the retrospective studies due to a lack of randomization.
The three studies by Eagle et al. ${ }^{27}$ and Backe et $a .^{28,29}$ were rated lower in quality because patients were enrolled after variable periods of time after having received coronary revascularization, contributing to heterogeneity of treatment effects. Subgroup analysis showed that the amount of time between coronary revascularization and subsequent high-risk noncardiac surgery may have caused a difference for the longterm mortality outcome, although not statistically significant. Patients who had coronary revascularization after being enrolled into the studies tend to have better long-term survival (OR 0.54, 95\% CI 0.15-1.91) than those who had the procedure performed a period of time prior to noncardiac surgery (OR 1.39, 95\% CI 0.86-2.25), in comparison with patients who received medical management (Table IV). 
TABLE IV Random effect odds ratios (95\% confidence interval) for coronary revascularization vs medical management in subgroup analyses

\begin{tabular}{|c|c|c|c|c|c|}
\hline Subgroups & Pre NCS death & Post NCS death & Post NCS MI & Long-term mortality & $\begin{array}{l}\text { Late adverse } \\
\text { cardiac events }\end{array}$ \\
\hline \multicolumn{6}{|c|}{ Total including CARP trial } \\
\hline Yes & $8.86(1.55-50.5)$ & $0.85(0.48-1.50)$ & $0.95(0.44-2.08)^{*}$ & $0.81(0.40-1.63)^{*}$ & $1.65(0.70-3.86)$ \\
\hline No & $6.37(0.25-163) \dagger$ & $0.87(0.41-1.88)$ & $0.95(0.29-3.14)^{*}$ & $0.64(0.12-3.34)^{*}$ & $1.65(0.70-3.86)$ \\
\hline \multicolumn{6}{|c|}{ Patients data from after 1980} \\
\hline Yes & $8.86(1.55-50.5)$ & $1.18(0.63-2.20)$ & $1.30(0.82-2.06)$ & $0.81(0.40-1.63)^{*}$ & $1.65(0.70-3.86)$ \\
\hline $\mathrm{No}^{27}$ & $\mathrm{NA}$ & $0.50(0.26-0.98) \dagger$ & $0.30(0.13-0.70) \dagger$ & $\mathrm{NA}$ & $\mathrm{NA}$ \\
\hline \multicolumn{6}{|c|}{ CR performed after enrolment } \\
\hline Yes & $8.86(1.55-50.5)$ & $0.95(0.47-1.90)$ & $1.16(0.70-1.94)$ & $0.54(0.15-1.90)^{*}$ & $1.28(0.30-5.39)$ \\
\hline $\mathrm{No}^{27-29}$ & NA & $1.06(0.20-5.67)^{*}$ & $0.77(0.10-5.31)^{*}$ & $1.39(0.86-2.25) \dagger$ & $2.27(1.37-3.77) \dagger$ \\
\hline
\end{tabular}

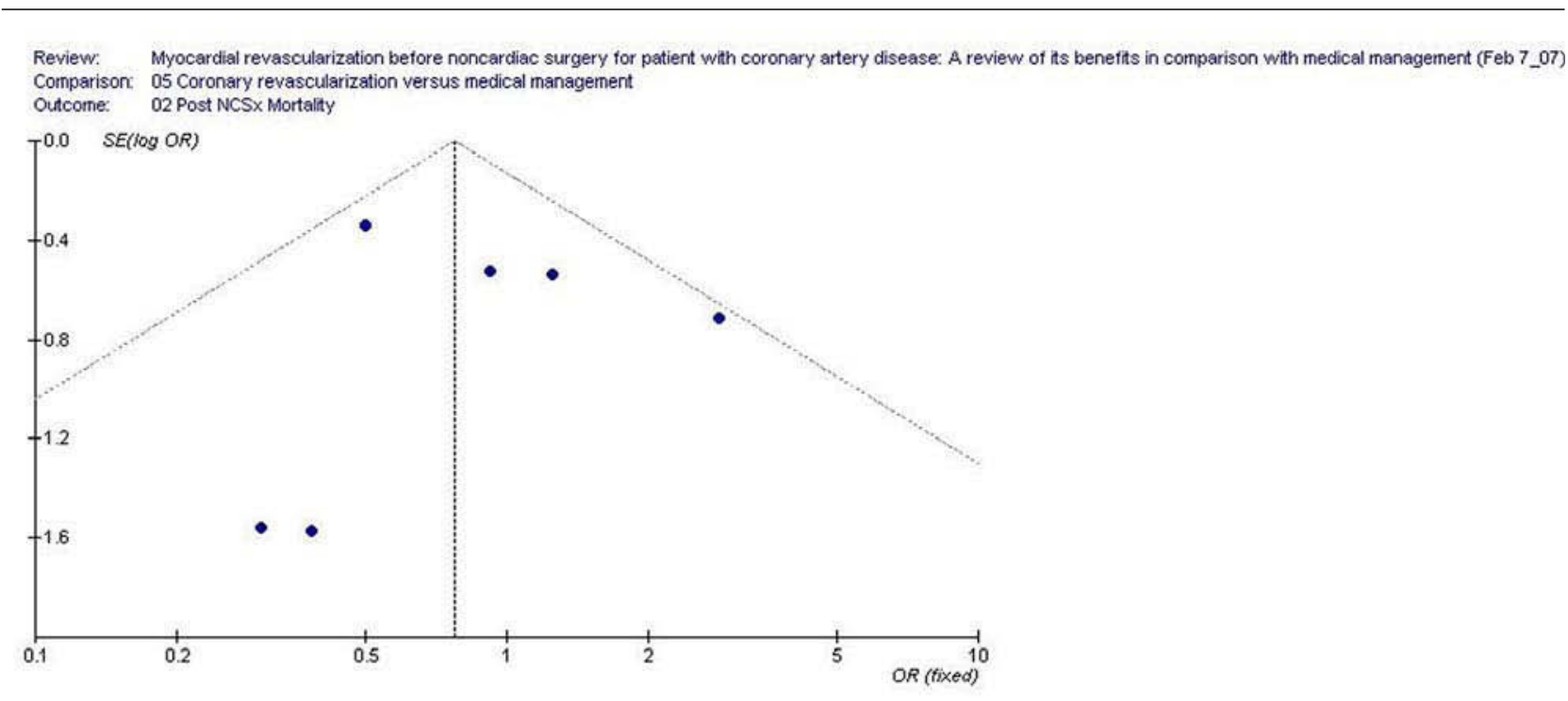

FIGURE 4 Funnel plot for post-noncardiac surgery mortality: results from each of the six relevant studies are represented. The $95 \%$ confidence interval line is also displayed.

\section{Discussion}

Results of the only randomized controlled trial available, the Coronary Artery Revascularization Prophylaxis Trial (CARP trial), ${ }^{22}$ demonstrated that there is no reduction in postoperative myocardial infarction, mortality, or long-term mortality among patients randomized to prophylactic coronary revascularization compared with patients allocated to optimized medical management before major vascular surgery. Our quantitative analyses of this CARP trial, as well as six retrospective studies, suggest a similar result: for patients with CAD scheduled for noncardiac surgery, prophylactic coronary revascularization does not reduce the odds of postoperative mortality, myocardial infarction, long-term mortality or late adverse cardiac events when compared with medical therapy. In fact, patients in the coronary revascularization group had increased odds of pre-noncardiac surgery mortality compared to those in the medical management group (OR 8.86, 95\% CI 1.55-40.5), 
highlighting the additional risk associated with the pre-surgical noncardiac surgery coronary revascularization intervention. These results, however, are based on a small number of perioperative mortality and cardiovascular events reported from the included studies. $^{22,27-32}$ Patient selection bias limits the strength of our conclusion, as well as its generalizability to patients with unstable or moderately-severe CAD. For example, the OR of pre-noncardiac surgery mortality among patients with coronary revascularization and those with medical management becomes non-significant when meta-analysis is performed excluding data from the CARP trials (OR 6.37, 95\% CI 0.25-163.1). This is likely caused by the differences in quality of study design and availability of complete patient data.

Eagle et $a l .{ }^{13}$ found that prior CABG, compared with medical management, significantly reduce perioperative cardiac events (myocardial infarction and death) after high-risk noncardiac surgery. Results from more recent studies failed to show prophylactic coronary revascularization to have cardiovascular/survival benefit ${ }^{22,28-32}$ (Table IV). This may be partly explained by improved perioperative medical therapy towards risk reduction, ${ }^{21,45}$ advances in surgical technology ${ }^{46}$ and reduced noncardiac surgical risk. ${ }^{47}$ However, one may argue that patients with worse prognosis were more likely to have been allocated to the revascularization group (selection bias); and that this particular subgroup of patients with more severe CAD may benefit from prophylactic coronary revascularization procedure before high-risk noncardiac surgery. Yet, due to the limited sample size and other potential biases, any subgroup statistical significance was not detected. In a recent retrospective study, Landesberg et al. ${ }^{48}$ examined records of 502 consecutive patients who underwent vascular surgery; patients with moderate-severe reversible ischemic disease on thallium scanning were referred for coronary angiography and, if appropriate, coronary revascularization before having high-risk vascular surgery. Multivariate analysis showed prophylactic coronary revascularization was associated with significant five-year survival (OR, 0.52; $P=0.018)$. When our meta-analysis was repeated including data from Landesberg's selective (group III and IV) patients, the pooled OR $(95 \% \mathrm{CI})$ for postoperative mortality was $0.81(0.50-1.32)$, and that for long-term mortality was $0.68(0.35-1.30)$. However, the between-study heterogeneity for long-term mortality remained highly significant $(P=0.003)$.

As suggested in the decision-making guideline by Fleisher et al. ${ }^{49}$ for major vascular surgery, recommendation to perform coronary revascularization prior to major vascular repair should involve weighing both the risks associated with coronary revascularization and the risk of the surgical procedure performed without preoperative interventions. The possibility exists for subgroups of patients with severe CAD in whom the risk of the vascular surgery, if performed without preoperative interventions, outweighs the combined risk of coronary revascularization and the surgical procedure. However, with advances in vascular procedural technology, ${ }^{47,50,51}$ and improvements in perioperative medical management, ${ }^{15,19-21,52}$ it is unlikely that prophylactic coronary revascularization will benefit patients undergoing noncardiac surgery except for patients in the highest risk category.

Lastly, from a health-economic standpoint, the cost-effectiveness of recommending prophylactic revascularization must also be considered when alternative medical management is as effective. The cost of performing both coronary intervention and then major vascular surgery, as suggested by Mason et al.,$^{53}$ was over $\$ 40,000$ in the 1990 s; a figure significantly higher than the alternative strategy of proceeding to vascular surgery with close monitoring of cardiac status $(\$ 24,300)$. Thus, medical therapy as a risk reduction strategy in patients with stable CAD is probably as effective as, and more cost-effective than, prophylactic coronary revascularization.-

A recent review by Kertai et $a l .{ }^{44}$ qualitatively summarized the role of preoperative revascularization before elective vascular surgery using current evidence from the CARP trial and relevant studies, and their findings were similar to ours in that the perioperative management of patients undergoing high-risk vascular surgery should involve weighing the risk benefit of extensive preoperative evaluation and risk management. The main differences between our systematic reviews relate to our more selective inclusion criteria and the methods adapted from Meta-analysis of Observational Studies in Epidemiology (MOOSE guideline $)^{54}$ to quantitatively determine if prophylactic coronary revascularization is beneficial in patients undergoing noncardiac surgery.

This study has several limitations. The strength of the conclusion is limited by the quality of reported studies. The systematic review comprised one randomized controlled trial and six retrospective studies. Although we are able to perform a quantitative analysis, the test for heterogeneity suggests significant differences in clinical population or methodological design amongst the studies. Secondly, six of seven studies enrolled vascular patients for elective high cardiac risk vascular surgeries, limiting the validity to extrapolate the result to other noncardiac surgeries. Outcomes for patients scheduled for urgent surgery 
of low to moderate cardiac risk are not considered in this review. Thirdly, among studies included in the meta-analyses, none randomly compared prophylactic CABG vs percutaneous coronary intervention in their effects on the primary outcomes of interest. Therefore, we could not comment on their relative efficacy.

According to the 2002 ACC/AHA guidelines for perioperative cardiovascular evaluation for noncardiac surgery, ${ }^{13}$ it is recommended that patients with intermediate risk undergoing high-risk surgery or with poor functional capacity, should undergo noninvasive testing and possibly prophylactic preoperative coronary revascularization. The rationale behind this recommendation is that prophylactic coronary revascularization may reduce perioperative mortality and morbidity. Our findings suggest that prophylactic coronary revascularization does not offer survival or cardiac protective benefit over medical management to patients, $60-70 \mathrm{yr}$ of age, with stable CAD before high-risk noncardiac/vascular surgery (Grade D recommendation, Appendix D). A paradigm shifting towards preoperative medical therapy including betablockers, statin and aspirin therapy may be more costbeneficial compared to prophylactic revascularization. The 2006 ACC/AHA guideline ${ }^{15}$ update focusing on perioperative beta-blocker may reflect a shift in perioperative strategy in favour of perioperative medical management over prophylactic coronary revascularization. Our systematic review, comprising one randomized controlled trial and six retrospective studies, has a limited ability to extrapolate to our current patient population. It also highlights the urgent need for adequately powered randomized controlled trials to provide the answer to the question: Does prophylactic coronary revascularization improve patient outcome compared to medical management in patients undergoing noncardiac surgery? If so, which patient subset(s) will derive significant benefit in outcome?

\section{Acknowledgement}

We thank Dr. Joseph Beyene of the Cochrane Collaboration for his statistical advice, Ms. Margaret Fulford of the Harry R. Abbott Dentistry Library for her research assistance, and Dr. Daniel A. Hass for his support of this project.

\section{APPENDIX A Search strategy}

Electronic search of bibliographical databases

Source searched: ten electronic bibliographic databases were searched:
- Ovid Medline (1966-2006 Feb, in-process \& other non-indexed citations),

- EMBASE (1980-2006),

- Cumulative Index to Nursing \& Allied Health Literature (CINAHL),

- Evidence Based Medicine of Cochrane Central Register of Controlled Trials,

- Cochrane Database of Systematic Reviews.

- Database of Abstracts of Reviews of Effects (DARE)

- The Cochrane Central Register of Controlled trials (CENTRAL)

- NHS Economic Evaluation Database (NHS EED)

- Conference Paper Index

- ISI proceedings

EMBASE search strategy included noncardiac surgical or noncardiac surgery or [surgery (exp) AND statistics (exp)] or [surgery (exp) AND surgical mortality (exp)] or intraoperative period (exp) or postoperative complication (exp) or preoperative period (exp)

$A N D$

(coronary artery surgery or coronary artery bypass graft or coronary artery bypass surgery or coronary artery recanalization or coronary reperfusion or heart muscle revascularization) or angioplasty (exp)

\section{AND}

Heart muscle ischemia (exploded to drug therapy) or coronary artery atherosclerosis (exploded to drug therapy) or coronary artery obstruction (exploded to drug therapy) or coronary artery spasm (exploded to drug therapy) or (medical management AND (heart muscle ischemia (exploded) or coronary artery atherosclerosis (exploded) or coronary artery obstruction (exploded) or coronary artery spasm (exploded))

Medline search strategy included noncardiac surgical or noncardiac surgery or surgical procedures (exploded to subcategory adverse effect, contraindications, statistics \& numerical data, mortality) or perioperative care or postoperative care (subcategory adverse effects, mortality, rehabilitation, statistics \& numerical data, therapy), or postoperative period (exploded) or preoperative care

$A N D$

Myocardial revascularization (exploded) or angioplasty (exploded)

$A N D$

Myocardial ischemia (exploded to subcategory drug therapy) AND (medical management or medical therapy or drug therapy) 


\section{APPENDIX B Critical Appraisal Skills Program (CASP) - Critical appraisal tools ${ }^{24}$}

The CASP appraisal tools are provided and produced by the Critical Appraisal Skills Program (CASP), part of the Public Health Resource Unit (PHRU) based in Oxford, England. http://www.phru.nhs.uk/casp/ critical_appraisal_tools.htm

One mark is given to each question. Total score for CASP critical appraisal - cohort study is 12. Total score for CASP critical appraisal - randomized control trial is 10 .

Copy of the two CASP appraisal tools employed is available as Additional Material at www.cja-jca.org.

\section{APPENDIX C $^{55}$ http://www.ctfphc.org}

Canadian Task Force for Preventive Health Care Level of evidence - Research quality rating

I Evidence from randomized controlled trial(s)

II Evidence from controlled trial(s) without randomization

II-2 Evidence from cohort or case-control analytic studies, preferably from more than one centre or research group

II-3 Evidence from comparison between times or places with or without the intervention; dramatic results in uncontrolled experiments could be included here

III Opinions of respected authorities, based on clinical experience; descriptive studies or reports of expert committees

\section{APPENDIX D ${ }^{55}$ (http://www.ctfphc.org $/$ )}

Canadian Task Force (CTF) for Preventive Health Care

Recommendation grades for specific clinical preventive actions

A The CTF concludes that there is good evidence to recommend the clinical preventive action.

B The CTF concludes that there is fair evidence to recommend the clinical preventive action.

C The CTF concludes that the existing evidence is conflicting and does not allow making a recommendation for or against use of the clinical preventive action, however other factors may influence decision-making.

D The CTF concludes that there is fair evidence to recommend against the clinical preventive action.

E The CTF concludes that there is good evidence to recommend against the clinical preventive action.

I The CTF concludes that there is insufficient evidence (in quantity and/or quality) to make a recommendation, however other factors may influence decision-making.

\section{References}

I Mangano DT, Browner WS, Hollenberg M, London MJ, Tubau JF, TateoI IM. Association of perioperative myocardial ischemia with cardiac morbidity and mortality in men undergoing noncardiac surgery. The Study of Perioperative Ischemia Research Group. N Engl J Med 1990; 323: 1781-8.

2 Mangano DT, Goldman L. Preoperative assessment of patients with known or suspected coronary disease. N Engl J Med 1995; 333: 1750-6.

3 Detsky AS, Abrams HB, McLaughlin JR, et al. Predicting cardiac complications in patients undergoing non-cardiac surgery. J Gen Intern Med 1986; 1: 211-9.

4 Larsen SF, Olesen KH, Jacobsen E, et al. Prediction of cardiac risk in non-cardiac surgery. Eur Heart J 1987; 8: 179-85.

5 Lee TH, Marcantonio ER, Mangione CM, et al. Derivation and prospective validation of a simple index for prediction of cardiac risk of major noncardiac surgery. Circulation 1999; 100: 1043-9.

6 Fleisher LA, Eagle KA. Clinical practice. Lowering cardiac risk in noncardiac surgery. N Engl J Med 2001; 345: 1677-82.

7 Landesberg G, Shatz V, Akopnik I, et al. Association of cardiac troponin, CK-MB, and postoperative myocardial ischemia with long-term survival after major vascular surgery. J Am Coll Cardiol 2003; 42: 1547-54.

8 Grayburn PA, Hillis LD. Cardiac events in patients undergoing noncardiac surgery: shifting the paradigm from noninvasive risk stratification to therapy. Ann Intern Med 2003; 138: 506-11.

9 Anonymous. Invasive compared with non-invasive treatment in unstable coronary-artery disease: FRISC II prospective randomised multicentre study. Fragmin and Fast Revascularisation during InStability in Coronary artery disease Investigators. Lancet 1999; 354: 708-15.

10 Wallentin L, Lagerqvist B, Husted S, Kontny F, Stable E, Swahn E. Outcome at 1 year after an invasive compared with a non-invasive strategy in unstable coronaryartery disease: the FRISC II invasive randomised trial. FRISC II Investigators. Fast Revascularisation during InStability in Coronary artery disease. Lancet 2000; 356: 9-16. 
11 Kontny F. Improving outcomes in acute coronary syndromes--the FRISC II trial. Clin Cardiol 2001; 24(3 Suppl): 3-7.

12 Janzon M, Levin LA, Swahn E. Invasive treatment in unstable coronary artery disease promotes healthrelated quality of life: results from the FRISC II trial. Am Heart J 2004; 148: 114-21.

13 Eagle KA, Berger PB, Calkins H, et al. ACC/AHA Guideline Update for Perioperative Cardiovascular Evaluation for Noncardiac Surgery--Executive Summary. A report of the American College of Cardiology/American Heart Association Task Force on Practice Guidelines (Committee to Update the 1996 Guidelines on Perioperative Cardiovascular Evaluation for Noncardiac Surgery). Anesth Analg 2002; 94: 1052-64.

14 Snow V, Barry P, Fibn SD, et al. Primary care management of chronic stable angina and asymptomatic suspected or known coronary artery disease: A clinical practice guideline from the American College of Physicians. Ann Intern Med 2004; 141: 562-7.

15 Fleisher LA, Beckman JA, Brown KA, et al.. ACC/AHA 2006 guideline update on perioperative cardiovascular evaluation for noncardiac surgery: focused update on perioperative beta-blocker therapy: a report of the American College of Cardiology/American Heart Association Task Force on Practice Guidelines (Writing Committee to Update the 2002 Guidelines on Perioperative Cardiovascular Evaluation for Noncardiac Surgery): developed in collaboration with the American Society of Echocardiography, American Society of Nuclear Cardiology, Heart Rhythm Society, Society of Cardiovascular Anesthesiologists, Society for Cardiovascular Angiography and Interventions, and Society for Vascular Medicine and Biology. Circulation 2006; 113: 2662-74.

16 Mangano DT, Layng EL, Wallace A, Tateo I. Effect of atenolol on mortality and cardiovascular morbidity after noncardiac surgery. Multicenter Study of Perioperative Ischemia Research Group. N Engl J Med 1996; 335: 1713-20.

17 Poldermans D, Boersma E, Bax JJ, et al. The effect of bisoprolol on perioperative mortality and myocardial infarction in high-risk patients undergoing vascular surgery. Dutch Echocardiographic Cardiac Risk Evaluation Applying Stress Echocardiography Study Group. N Engl J Med 1999; 341: 1789-94.

18 Landesberg $G$. The pathophysiology of perioperative myocardial infarction: facts and perspectives. J Cardiothorac Vasc Anesth 2003; 17: 90-100.

19 Wijeysundera DN, Beattie WS. Calcium channel blockers for reducing cardiac morbidity after noncardiac surgery: a meta-analysis. Anesth Analg
2003; 97: 634-41.

20 Wijeysundera DN, Naik JS, Beattie WS. Alpha-

2 adrenergic agonists to prevent perioperative cardiovascular complications: a meta-analysis. Am J Med 2003; 114: 742-52.

21 Devereaux PJ, Goldman L, Yusuf S, Gilbert K, Leslie $K$, Guyatt GH. Surveillance and prevention of major perioperative ischemic cardiac events in patients undergoing noncardiac surgery: a review. CMAJ 2005; 173: 779-88.

22 McFalls EO, Ward HB, Moritz TE, et al. Coronaryartery revascularization before elective major vascular surgery. N Engl J Med 2004; 351: 2795-804.

23 Gould KL. New concepts and paradigms in cardiovascular medicine: the noninvasive management of coronary artery disease. Am J Med 1998; 104: 2S-17S.

24 Critical Appraisal Skills Programme (CASP) and Evidence-Based Practice. United Kingdom: Publich Health Resource Unit, 2006 May 22 [cited February 28, 2006]. Available from URL; http://www.phru. nhs.uk/casp/casp.htm.

25 Canadian Task Force on Preventive Health Care (CTFPHC). History/Methodology. Canada, 2003 August 5 [cited February 28, 2006]. Available from URL; http://www.ctfphc.org/.

26 Egger M, Smith GD, Phillips AN. Meta-analysis: principles and procedures. BMJ 1997; 315: 1533-7.

27 Eagle KA, Ribal CS, Mickel MC, Holmes DR, Foster $E D$, Gersh BJ. Cardiac risk of noncardiac surgery: influence of coronary disease and type of surgery in 3368 operations. CASS Investigators and University of Michigan Heart Care Program. Coronary Artery Surgery Study. Circulation 1997; 96: 1882-7.

28 Back MR, Stordabl N, Cutbbertson D, Johnson BL, Bandyk DF. Limitations in the cardiac risk reduction provided by coronary revascularization prior to elective vascular surgery. J Vasc Surg 2002; 36: 526-33.

29 Back MR, Leo F, Cuthbertson D, Johnson BL, Shamesmd $M L$, Bandyk $D F$. Long-term survival after vascular surgery: specific influence of cardiac factors and implications for preoperative evaluation. J Vasc Surg 2004; 40: 752-60.

30 Takahashi J, Okude J, Gohda T, et al. Coronary artery bypass surgery in patients with abdominal aortic aneurysm: detection and treatment of concomitant coronary artery disease. Ann Thorac Cardiovasc Surg 2002; 8: 213-9.

31 Garofalo M, Nardi P, Borioni R, Del Giudice C, Pellegrino A, Chiariello L. The impact of coronary revascularization on long-term outcomes after surgical repair of abdominal aortic aneurysm (Italian). Ital Heart J Suppl 2005; 6: 369-74.

32 Godet G, Riou B, Bertrand M, et al. Does preoperative 
coronary angioplasty improve perioperative cardiac outcome? Anesthesiology 2005; 102: 739-46.

33 Hassan SA, Hlatky MA, Boothroyd DB, et al. Outcomes of noncardiac surgery after coronary bypass surgery or coronary angioplasty in the Bypass Angioplasty Revascularization Investigation (BARI). Am J Med 2001; 110: 260-6.

34 Posner KL, Van Norman GA, Chan V. Adverse cardiac outcomes after noncardiac surgery in patients with prior percutaneous transluminal coronary angioplasty. Anesth Analg 1999; 89: 553-60.

35 Katritsis DG, Ioannidis JP. Percutaneous coronary intervention versus conservative therapy in nonacute coronary artery disease: a meta-analysis. Circulation 2005; 111: 2906-12.

36 Hueb W, Soares PR, Gersh BJ, et al. The medicine, angioplasty, or surgery study (MASS-II): a randomized, controlled clinical trial of three therapeutic strategies for multivessel coronary artery disease: one-year results. J Am Coll Cardiol 2004; 43: 1743-51.

37 Anonymous. Coronary artery surgery study (CASS): a randomized trial of coronary artery bypass surgery. Comparability of entry characteristics and survival in randomized patients and nonrandomized patients meeting randomization criteria. J Am Coll Cardiol 1984; 3: 114-28.

38 Varnauskas E. Twelve-year follow-up of survival in the randomized European Coronary Surgery Study. N Engl J Med 1988; 319: 332-7.

39 Tusuf S, Zucker D, Chalmers TC. Ten-year results of the randomized control trials of coronary artery bypass graft surgery: tabular data compiled by the collaborative effort of the original trial investigators. Part 1 of 2 . Online J Curr Clin Trials 1994; Doc No 145.

40 Yusuf S, Zucker D, Chalmers TC. Ten-year results of the randomized control trials of coronary artery bypass graft surgery: tabular data compiled by the collaborative effort of the original trial investigators. Part 2 of 2 . Online J Curr Clin Trials 1994; Doc No 144.

41 Rihal CS, Eagle KA, Mickel MC, Foster ED, Sopko G, Gersh BJ. Surgical therapy for coronary artery disease among patients with combined coronary artery and peripheral vascular disease. Circulation 1995; 91: 46-53.

42 Kakisis JD, Abir F, Liapis CD, Sumpio BE. An appraisal of different cardiac risk reduction strategies in vascular surgery patients. Eur J Vasc Endovasc Surg 2003; 25: 493-504.

43 Farid I, Litaker D, Tetzlaff JE. Implementing ACC/ AHA guidelines for the preoperative management of patients with coronary artery disease scheduled for noncardiac surgery: effect on perioperative outcome. J Clin Anesth 2002; 14: 126-8.

44 Kertai MD, Bogar L, Gal J, Poldermans D. Pre- operative coronary revascularization: an optimal therapy for high-risk vascular surgery patients? Acta Anaesthesiol Scand 2006; 50: 816-27.

45 Devereaux PJ, Goldman L, Cook DJ, Gilbert K, Leslie $K$, Guyatt $G H$. Perioperative cardiac events in patients undergoing noncardiac surgery: a review of the magnitude of the problem, the pathophysiology of the events and methods to estimate and communicate risk. CMAJ 2005; 173: 627-34.

46 Martens TP, Argenziano M, Oz MC. New technology for surgical coronary revascularization. Circulation 2006; 114: 606-14.

47 Prinssen $M$, Verhoeven EL, Buth J, et al. A randomized trial comparing conventional and endovascular repair of abdominal aortic aneurysms. N Engl J Med 2004; 351: 1607-18.

48 Landesberg G, Mosseri M, Wolf YG, et al. Preoperative thallium scanning, selective coronary revascularization, and long-term survival after major vascular surgery. Circulation 2003; 108: 177-83.

49 Fleisher LA, Skolnick ED, Holroyd KJ, Lehmann HP. Coronary artery revascularization before abdominal aortic aneurysm surgery: a decision analytic approach. Anesth Analg 1994; 79: 661-9.

50 Greenhalgh RM, Brown LC, Kwong GP, Powell JT, Thompson SG, EVAR trial participants. Comparison of endovascular aneurysm repair with open repair in patients with abdominal aortic aneurysm (EVAR trial 1), 30-day operative mortality results: randomised controlled trial. Lancet 2004; 364: 843-8.

51 Blankensteijn JD, de Jong SE, Prinssen M, et al. Twoyear outcomes after conventional or endovascular repair of abdominal aortic aneurysms. N Engl J Med 2005; 352: 2398-405.

52 Briel M, Studer M, Glass TR, Bucher HC. Effects of statins on stroke prevention in patients with and without coronary heart disease: a meta-analysis of randomized controlled trials. Am J Med 2004; 117 : 596-606.

53 Mason JJ, Owens DK, Harris RA, Cooke JP, Hlatky $M A$. The role of coronary angiography and coronary revascularization before noncardiac vascular surgery. JAMA 1995; 273: 1919-25.

54 Stroup DF, Berlin JA, Morton SC, et al. Meta-analysis of observational studies in epidemiology: a proposal for reporting. Meta-analysis Of Observational Studies in Epidemiology (MOOSE) group. JAMA 2000; 283: 2008-12.

55 Anonymous. Guidelines for assessing and managing the perioperative risk from coronary artery disease associated with major noncardiac surgery. American College of Physicians. Ann Intern Med 1997; 127: 309-12. 